\title{
RESEARCH
}

Open Access

\section{Role of advanced glycation end products and sorbitol dehydrogenase in the pathogenesis of diabetic retinopathy}

Leqaa A. Moemen ${ }^{1 *}$, Mona A. Abdel Hamid', Soher Abdel Wahab', Mahmoud Kenawy M. Kenawy', Manal H. Abuelela², Olfat A. Hassanin ${ }^{3}$, Marwa A. Fouly ${ }^{3}$, Amira A. Abdelazeem4, Shahira Riad Noweir4, Somaia M. Ismail ${ }^{5}$, Yara Hossam Eldin R. Abdel Gawad², Safa Refaat ${ }^{6}$, Azza K. Amer, Nervana A. Khalaf ${ }^{7}$, Safya H. Aboelmakarem ${ }^{7}$, Mehry S. Elsobky ${ }^{7}$, Mona R. Abdelrasool ${ }^{7}$, Sherif S. Karawya ${ }^{3}$ and Zeinab M. Osman ${ }^{3}$

\begin{abstract}
Background: Diabetic retinopathy is one of the common microvascular complications of diabetes. The formation of advanced glycation end products (AGE) exerts deleterious effects by acting directly to induce cross-linking of proteins promoting vascular damage. Hyperglycemia causes disturbance in glycogenesis pathway resulting in reduction of glucose to sorbitol which is converted to fructose by sorbitol dehydrogenase.
\end{abstract}

Methods: The levels of advanced glycation end products (AGE), lipid profile, and glycosylated Hb were estimated in 266 type I diabetic patients without retinopathy, patients with nonproliferative diabetic retinopathy (NPDR), and proliferative diabetic retinopathy patients (PDR).The association between genotypes of two polymorphisms of sorbitol dehydrogenase gene (SDH) was estimated in the promoter region: a C/G transversion located at_1214 position and a G/C transversion at_888 position. This study showed allele-specific PCR for C-1214G polymorphism and restriction fragment length polymorphism (RFLP) technique for a G/C transversion at _ 888 position.

Results: Significant increase was detected in glycosylated Hb levels in diabetic group, both with retinopathy and without retinopathy. Also, a significant increase in $\mathrm{Hb1c}$ in PDR group compared to NPDR. Significant increase in total cholesterol, HDL, TG, and AGE in PDR group compared to the group without retinopathy. No significant change was observed in the same parameter between PDR and NPDR group. Significant increase in AGE in both PDR and NPDR group compared to the group without retinopathy. No significant change in PDR group compared to NPDR.

The results of this study showed no significant difference in genotype distribution (C/C, C/G, G/G) of the $C-1214 G$ polymorphism between the two groups of patients with and without DR A2-. There was no statistically significant difference between the three genotypes (CC, CG, and $G G$ ) of the $C-1214 G$ polymorphism in relation to DR severity in male genders. However, there was a statistically significant difference in female gender with increased frequency of CC genotype $(2.7 \%, 21.9 \%$, and $23.7 \%)$.

There was no significant difference in genotype distribution ( $C / C, G / C$, and $G / G)$ of the $G-888 C$ polymorphism between the two groups of patients with DR and without DR. However, the CC genotype occurred more frequently in patients with DR than patients without DR (6.7\% vs. 3.9\%), and G/G genotype occurred more frequently in (Continued on next page)

\footnotetext{
* Correspondence: leqaa.moemen@yahoo.com

${ }^{1}$ Medical Biochemistry, Research institute of Ophthalmology, Giza, Egypt

Full list of author information is available at the end of the article
}

\section{Springer Open}

(๑) The Author(s). 2020 Open Access This article is licensed under a Creative Commons Attribution 4.0 International License, which permits use, sharing, adaptation, distribution and reproduction in any medium or format, as long as you give appropriate credit to the original author(s) and the source, provide a link to the Creative Commons licence, and indicate if changes were made. The images or other third party material in this article are included in the article's Creative Commons licence, unless indicated otherwise in a credit line to the material. If material is not included in the article's Creative Commons licence and your intended use is not permitted by statutory regulation or exceeds the permitted use, you will need to obtain permission directly from the copyright holder. To view a copy of this licence, visit http://creativecommons.org/licenses/by/4.0/. 


\begin{abstract}
(Continued from previous page)
patients without DR than patients with DR (0.70.6 vs. 0.59.7).

There was no statistically significant influence of the three genotype (GG, GC, and CC) polymorphism on DR progression in both genders. However, there was an increased frequency of CC genotypes polymorphism with severity in both genders $(0.0 \%, 4.2 \%, 6.9 \%)$ in males and $(5.6 \%, 6.3 \%, 8.8 \%)$ in females.

Conclusion: The onset of diabetic retinopathy is multifactorial, and a cascade of hyperglycemia-oxidative pathways has been involved in the initiation and progression of this disease. However, further research is required to understand the cellular and molecular mechanism of diabetic retinopathy pathogenesis. So that novel anti-diabetic retinopathy strategies can be developed, aiming to reduce the major economical and medical burden caused by diabetic retinopathy.
\end{abstract}

Keywords: Advanced glycation end products, Sorbitol dehyderogenas, Diabetic retinopathy

\section{Introduction}

Diabetes is a microvascular disorder characterized by hyperglycemia. It is mostly considered to be the major cause of diabetic complications (retinopathy, nephropathy, and neuropathy) in both types 1 and 2 diabetes (Wan et al. 2015). One mechanism linking chronic hyperglycemia with diabetic retinopathy is the formation and accumulation of advanced glycation end products (AGE) (Madonna et al. 2017).

Formation of advanced glycation end products (AGE) correlates with glycemic control. They exert deleterious effects by acting directly to induce cross-linking of longlived proteins to promote vascular stiffness, altering vascular structure, and function and interacting with receptor for AGE to induce intracellular signaling leading to enhanced oxidative stress and elaboration of key proinflammatory cytokines (Kandarakis et al. 2014).

AGE effects include production of reactive oxygen species (ROS), binding to specific cell surface receptors and forming cross-links and contributing to the pathophysiology of vascular disease in diabetes. AGEs bind to specific cellular proteins changing the local concentrations of cytokines and growth factors resulting in accumulation in the vessel wall which may contribute to acceleration of diabetic retinopathy (Takeuchi and Yamagishi 2009).

Morphological and functional changes in diabetic retinopathy include basement membrane thickening, loss of pericytes, and increased permeability (Katagiri et al. 2017). Resulting in vascular leakage (Choudhuri et al. 2013) and leading to occlusion and ischemia (Warboys et al. 2009) along with induction of vascular endothelial growth factor (VEGF), result in angiogenesis and neovascularization (Prasad and Mishra 2018).

Polyol pathway (sorbitol-aldose reductase pathway) activation represents one of the processes observed under the hyperglycemia-induced oxidative stress conditions during DR pathogenesis (Pusparajah et al. 2016). Glucose is reduced to sorbitol and subsequently oxidized to fructose, with the help of two enzymes: aldose reductase, which converts glucose into sorbitol, and sorbitol dehydrogenase, which oxidize sorbitol into fructose (Kim et al. 2012). Hyperglycemia leads to an imbalance between glycogenesis and glycolysis pathway favoring the accumulation of sorbitol (Liu et al. 2016). Also, sorbitol and fructose accumulation in cells are leading to increase in osmotic pressure and membrane permeability damage.

Under hyperglycemic conditions, polyol pathway activity increases, which is followed by a decrease in the levels of NADPH that can regenerate an intracellular antioxidant, GSH (Romeo et al. 2002), leading to the accumulation of ROS, which induces oxidative stress in cells (Liu et al. 2016). Also, the reduction of NAD+ into $\mathrm{NADH}$, due to hypoxia and redox imbalance, increases intracellular NADH levels, leading to cell edema, structural alterations, metabolic disorders, and microvascular lesion (Jing et al. 2012).

The aim of this study is predicting diabetic retinopathy among Egyptian patients with type I diabetes by measuring the levels of AGE products in serum of those patients together with detecting the genetic polymorphisms of sorbitol dehydrogenase. We will investigate the association between genotypes of two polymorphisms of sorbitol dehydrogenase gene $(\mathrm{SDH})$ in the promoter region: a $\mathrm{C} / \mathrm{G}$ transversion located at_1214 position and a G/C transversion at 888 position. So that novel anti-AGE strategies can be developed, aiming to reduce the major economical and medical burden caused by diabetic retinopathy.

\section{Subjects and methods}

\section{Study design and sample size}

A cross-sectional, observational study was undertaken in a sample of type I diabetic patients who attend diabetes polyclinic of RIO's hospital, Giza, Egypt, between October 2012 and December 2016 and who were willing to participate. The sampling procedure consisted of randomly selecting 2 days each week (Sunday and Wednesday) and recruiting all the diabetic patients (type I) who attended on those days to be the study population. A comprehensive data was collected from patients with 
type I diabetes with the aim of identifying genetic and environmental risk factors for diabetic complications. In the first visit, a detailed history followed by baseline blood samples for fasting blood sugar (FBS) and glycosylated hemoglobin (HBA1c) were obtained to confirm DM. Once confirmed, all patients were referred to the Ophthalmic Department of the diabetic polyclinic. Written informed consents were obtained from all subjects in accordance with the principles of the Declaration of Helsinki. The protocol of the study was approved by the RIO Ethics Committee; a venous blood sample was collected from each subject after the consent form had been signed.

\section{Inclusion criteria}

1. Participants diagnosed to have diabetes mellitus without diabetic retinopathy were included in this study.

2. Participants diagnosed to have diabetes mellitus with diabetic retinopathy were also included.

\section{Exclusion criteria}

1. Participants with known other systemic diseases which could manifest as retinal pathological lesions such as hypertensive retinopathy.

2. Participants with very hazy ocular media which obscure the ocular fundus.

3. Gestational diabetics.

4. Participants not accepting the informed consent.

Two hundred and sixty-six type I diabetic patients were studied. (108 males, 158 females) aged $41.7+12.5$ (mean $\pm \mathrm{SD}$ ) years. They were diabetic for $>5$ years.

All patients in our study were subjected to:

1. Full medical examination

2. Full ophthalmic examination

3. Laboratory Investigations

4. Genetic examination

\section{Medical examination}

Full personal, family, and medical history include a standardized questionnaire for cardiovascular disease. The following parameters were collected: gender, age of onset of diabetes, and duration of diabetes.

Full medical examination:

- Cardiovascular examination and ECG.

- Blood pressure was measured twice in a sitting position using a mercury sphygmomanometer and after rest of at least 10 minutes.
- Investigations for other diabetic complications as neuropathy and nephropathy.

- Monthly follow-up of patients with uncontrolled blood sugar levels.

\section{Ophthalmic examination}

Complete ophthalmological examination including:

- Absolute visual acuity

- Intraocular pressure using slit lamp applanation tonometer or air buff tonometer

- Pin torch external eye examination to screen for extra ocular abnormalities

- Anterior segment biomicroscopic examination

- Fundus examination using slit lamp biomicroscopy after full dilation of the pupil using cyclopentolate $1 \%$ eye drop

- Fluorescein fundus angiography (FFA) using fundus camera (TRC50EX) and intravenous injection of 5 $\mathrm{ml} 10 \%$ sodium fluorescein solution

- The pictures were studied to categorize the different phenotypes of DR according to FFA as being mentioned in the phenotypes classification of DR (A.B.C). Also a report on the state of macular area was done for the presence or absence of edema

\section{Laboratory investigation}

Sample collection: venous blood samples $(10 \mathrm{ml})$ were withdrawn from all subjects and emptied on:

- Sterile ethylene diamine-tetra-acetate "EDTA" vacutainer $(2 \mathrm{ml})$ tubes used for DNA extraction and HbA1c. HbA1c was extracted using the Lobona system. DNA was extracted from blood samples and stored at $-30{ }^{\circ} \mathrm{C}$ till time of assay

- Sterile fluoride vacutainer tube for blood sugar (2 $\mathrm{ml}$ )

- Sterile plain vacutainer tube $(6 \mathrm{ml})$ was centrifuged, and the serum was stored at $-20^{\circ} \mathrm{C}$ to measure the rest of the parameters. Lipid profile [total cholesterol, high density lipoprotein (HDLcholesterol), low density lipoprotein (LDLcholesterol) and triglycerides] using regular commercial kits. Urea and creatinine using commercial kits and Glycation end products (GEP) using immune-sorbent assay (ELISA) kits

\section{Biochemical methods}

- HbA1c was extracted using the Lobona system (American Diabetes Association 2010)

- Lipid profile, total cholesterol, high-density lipoprotein (HDL-cholesterol), low-density lipoprotein 
(LDL-Cholesterol), and triglycerides using regular commercial kits

- Glycation end products using immune-sorbent assay (ELISA) kits (Onarato et al. 2000)

\section{Genetic study}

One hundred and ninety patients were examined at the ophthalmic clinic for diabetic patients; 133 were diagnosed as having DR based on the ophthalmologist's examination. Also, a group of 57 diabetic patients without DR was taken as a control group. All were subjected to molecular genetic analysis to evaluate its association with two selected candidate genes proposed to be related to DR pathogenesis. We investigate the association between genotypes of two polymorphisms of sorbitol dehydrogenase gene $(\mathrm{SDH})$ in the promoter region: a $\mathrm{C} / \mathrm{G}$ transversion located at _1214 position (the C_1214G polymorphism) and a $\mathrm{G} / \mathrm{C}$ transversion at $\_888$ position (the G_888C polymorphism).

Full medical history includes name, age, sex, family history, parental consanguinity and complaints; also, the family pedigree was constructed, and a complete medical genetic examination was done for all participants.

Blood samples, $2 \mathrm{ml}$ peripheral blood on ethylene diamine tetra acetic acid (EDTA) tubes, were collected from all participants.

Extraction of DNA was done and stored at $-30{ }^{\circ} \mathrm{C}$.

\section{Allele-specific PCR for C-1214G polymorphism}

The genotypes of the C 1214G polymorphism were determined by using the following primers:

The two allele-specific:

C variant 5'-TGTTGCCCAGGCTGGTGTTC-3'

G variant 5' -TGTTGCCCAGGCTGGTGTTG-3'

The two control primers:

Forward 5' -TTTGGGCAGAAACTCTG-3'

Revers 5'-ACGCAGCGTCCACGTC-3'

\section{PCR conditions}

Thermo-Scientific kit was used for the PCR reactions. This includes the polymerase enzyme Taq DNA polymerase, dNTPs, and PCR Green buffer. Where each 20 $\mu \mathrm{l}$ of the PCR reaction contained Genomic DNA $6 \mathrm{ng}$ (3 $\mu \mathrm{l}), 2.5 \mu \mathrm{l}$ of $10 \times$ PCR buffer, $2.5 \mu \mathrm{l}$ dNTPs of dNTP mixture stock $(2 \mathrm{mM}), 2 \mu \mathrm{l}$ of $10.0 \mathrm{pmol}$ forward primer, $2 \mu \mathrm{l}$ of $10.0 \mathrm{pmol}$ reverse primer, Taq polymerase $2.5 \mathrm{U}$ $(0.5 \mu \mathrm{l})$, and PCR water nuclease free $7.5 \mu \mathrm{l}$

PCR was carried out on a Biometra ${ }^{\mathrm{Tm}}$ Thermal Cycler, (Model: TProfessional Basic) using the following conditions:

1. Initial denaturation step at $95{ }^{\circ} \mathrm{C}$ for $1 \mathrm{~min}$.

2. Denaturation at $95{ }^{\circ} \mathrm{C}$ for $30 \mathrm{~s}$.

3. Annealing temperature at $62{ }^{\circ} \mathrm{C}$ for $30 \mathrm{~s}$.
4. Extension for $30 \mathrm{~s}$ at $72{ }^{\circ} \mathrm{C}$.

5. Stages 2-4 carried out 35 times.

6. The final extension step was performed at $72{ }^{\circ} \mathrm{C}$ for $5 \mathrm{~min}$.

PCR products were separated onto a $2 \%$ agarose gel.

PCR was carried out on a Biometra ${ }^{\text {mi }}$ Thermal Cycler, (TProfessional Basic) using the following conditions table (IV): for G-888C polymorphism, each $20 \mu \mathrm{l}$ of the PCR reaction contained:

1. Genomic DNA $6 \mathrm{ng}(2.0 \mathrm{ng} / \mu \mathrm{l}$ equal to $3 \mu \mathrm{l})$.

2. $2.5 \mu \mathrm{l}$ of $10 \times$ PCR buffer.

3. $2.5 \mu \mathrm{l}$ dNTPs of dNTPs mixture stock $(2 \mathrm{mM})$.

4. $2 \mu \mathrm{l}$ of $10.0 \mathrm{pmol}$ forward primer.

5. $2 \mu \mathrm{l}$ of $10.0 \mathrm{pmol}$ reverse primer.

6. Taq polymerase $2.5 \mathrm{U}(0.5 \mu \mathrm{l})$.

7. PCR water nuclease free $7.5 \mu \mathrm{l}$

Forward Primer 5'CGCCCGGCCTCATGTCTTTT-3'

Reverse Primer 5'TTGGGGTGGGGAATGTGAGG3'

Each exon of interest (in the studied genes) was amplified using the suitable pair of primers via conventional Polymerase Chain Reaction (PCR) technique.

The PCR amplicons for each exon of interest were digested using the suitable restriction enzyme according to the Restriction Fragment length Polymorphism (RFLP) technique.

Horizontal agarose gel electrophoresis technique was used to detect the genotype(s) for each PCR product according to the size of DNA fragments after digestion.

The bands were detected via gel documentation system.

Excel (2016) was employed to perform the statistical analysis of the results.

\section{Statistical analysis}

All data was analyzed using the statistical package for social studies software (SPSS version 21). Descriptive analysis was conducted with the $X^{2}$ test for categorical variables. Fisher's exact test is a statistical significance test used in the analysis of contingency tables where sample sizes are small as opposed to the chi-square $\left(X^{2}\right)$ test that can be used with larger samples. Normally distributed variables were presented as the mean $( \pm \mathrm{SD})$ and non-normally distributed variables expressed as median (inter-quartile range).

Frequencies and percentages were calculated for all the qualitative data including gender, age group, and type of DR. logistic regression analyses, providing odds ratios (OR), their $95 \%$ confidence intervals $(\mathrm{CI}), p$ values, and Wald's chi-square estimates, were performed. $P$ values $<0.05$ were accepted as indicating statistical significance. In this study, the allele frequencies for each variant in patients and controls were tested for 
agreement with expectations using Fisher's exact test as a sort of chi-square $\left(X^{2}\right)$ test $(P \leq 0.05)$.

\section{Results}

A total of 266 type I diabetic patients (40.6\% males) were studied; male-to-female ratio was 1:1.46 (108:158). Mean age at ophthalmologic examination was $41.7 \pm 12.5$ years. Fifty-six percent of the studied patients had duration of DM > 10 years. Overall proportion of any DR was $71.4 \%(n=190)$. Eighty-five patients $(31.9 \%)$ had NPDR, and 105 patients (39.5\%) were diagnosed to have PDR. Our study revealed that history of hypertension, family history of diabetic retinopathy (DR), and duration of diabetes were correlated to the occurrence of DR. No significant correlation could be detected of gender, education, family history of diabetes, consanguinity, ischemic heart disease, nephropathy, and neuropathy to DR (Table 1).

There was a significant increase in HbA1c between groups with and without DR and between NDPR and PDR groups. Also, significant increase in $\mathrm{Hb} 1 \mathrm{c}$ in PDR group compared to NPDR. There was a significant increase in total cholesterol, HDL, TG, and glycated end product (AGE) in the group PDR compared to the group without retinopathy. There was a significant increase in AGE between the group in both and PDR and NPDR. No significant change in AGE in PDR group compared to NPDR (Table 2).

This study investigated the association between genotypes of polymorphisms of sorbitol dehydrogenase gene $(\mathrm{SDH})$ in the promoter region: a $\mathrm{C} / \mathrm{G}$ transversion located at _1214 position (the C_1214G polymorphism) (Table 3) (Fig. 1) and a G/C transversion at _888 position (the G_888C polymorphism) in relation to microangiopathies (Table 4) (Fig. 2). Table 5 was showed the distribution of genotype frequency of G-888C polymorphism of SDH gene in relation to severity (NPDR and PDR) of retinopathy in both genders.

Table 6 verified genotype frequency of C-1214G polymorphism of SDH gene in relation to severity (NPDR and PDR) of retinopathy in both genders.

\section{Clinical and laboratory features of type I DM patients}

From the above tables, significant increase is observed in the following:

- HbA1c between groups with and without DR and between NDPR and PDR groups

- Total cholesterol, HDL, TG, and GEP in the group without DR compared to the PDR group. The increase of HDL in PDR group can be explained by the fact that the main protein component of HDL is APO lipoprotein which is already high in type I DM
Table 1 Clinical characteristics of patients grouped according to the presence of DR

$\begin{array}{llll}\frac{\text { Retinopathy }}{\text { No }} \% & & \text { No retinopathy } & P \text { value } \\ & \text { No } & \%\end{array}$

\begin{tabular}{|c|c|c|c|c|c|}
\hline Gender & & & & & 0.430 \\
\hline Male & 80 & 74.1 & 28 & 25.9 & \\
\hline Female & 110 & 69.6 & 48 & 30.4 & \\
\hline Age & & & & & 0.004 \\
\hline$<30$ yrs & 30 & 56.6 & 23 & 43.4 & \\
\hline $30-40$ yrs & 43 & 65.2 & 23 & 34.8 & \\
\hline $41-60$ yrs & 104 & 78.2 & 29 & 21.8 & \\
\hline$>60$ yrs & 13 & 92.9 & 1 & 7.1 & \\
\hline Education & & & & & 0.343 \\
\hline Illiterate & 121 & 73.3 & 44 & 26.7 & \\
\hline Middle & 37 & 63.8 & 21 & 36.2 & \\
\hline High & 32 & 74.4 & 11 & 25.6 & \\
\hline Duration of diabetes & & & & & $<0.001$ \\
\hline$=<10 \mathrm{yrs}$ & 41 & 53.2 & 36 & 46.8 & \\
\hline $11-20$ yrs & 65 & 77.4 & 19 & 22.6 & \\
\hline$>20 \mathrm{yrs}$ & 84 & 80.0 & 21 & 20.0 & \\
\hline Control of diabetes & & & & & $<0.001$ \\
\hline Controlled & 64 & 51.6 & 60 & 48.4 & \\
\hline Uncontrolled & 126 & 88.7 & 16 & 11.3 & \\
\hline Family history of DR & & & & & 0.039 \\
\hline Positive & 37 & 82.2 & 8 & 17.8 & \\
\hline Negative & 66 & 65.3 & 35 & 34.7 & \\
\hline Unknown & 120 & nts dic & know & & \\
\hline History of Consang. & & & & & 0.246 \\
\hline Positive & 27 & 64.3 & 15 & 35.7 & \\
\hline Negative & 163 & 72.8 & 61 & 27.2 & \\
\hline Hypertension & & & & & 0.034 \\
\hline No & 114 & 68.3 & 53 & 31.7 & \\
\hline Yes & 58 & 81.7 & 13 & 18.3 & \\
\hline $\mathrm{IHD}$ & & & & & 0.737 \\
\hline No & 169 & 72.8 & 63 & 27.2 & \\
\hline Yes & 4 & 66.2 & 2 & 33.3 & \\
\hline Nephropathy & & & & & 0.198 \\
\hline No & 159 & 71.3 & 64 & 28.7 & \\
\hline Yes & 13 & 86.7 & 2 & 13.3 & \\
\hline Neuropathy & & & & & 0.375 \\
\hline No & 88 & 69.8 & 38 & 30.2 & \\
\hline Yes & 84 & 75.0 & 28 & 25.0 & \\
\hline
\end{tabular}

Clinical features of type I DM patients grouped according to the presence or absence of DR that are shown in Table 1. Patients with no DR had a shorter duration of DM and were younger than patients with DR. Gender proportion did not differ significantly among groups. The study revealed no significant correlation of gender, education, family history of diabetes, consanguinity, ischemic heart disease, nephropathy, and neuropathy to DR, whereas family history of DR and hypertension were correlated to retinopathy, and there was a highly significant correlation of duration of diabetes to retinopathy. 
Table 2 Laboratory investigations of diabetics grouped according to DR types

\begin{tabular}{|c|c|c|c|c|c|}
\hline & & No. & Mean & SD & $P$ value \\
\hline \multirow[t]{3}{*}{$\overline{\mathrm{FBS}}$} & No. & 76 & 223.4 & 76.4 & 0.835 \\
\hline & NPDR & 85 & 223.5 & 79.1 & \\
\hline & PDR & 105 & 217.4 & 84.0 & \\
\hline \multirow[t]{3}{*}{ PPBS } & No. & 76 & 286.3 & 81.2 & 0.437 \\
\hline & NPDR & 85 & 306.2 & 105.1 & \\
\hline & PDR & 105 & 295.8 & 103.1 & \\
\hline \multirow[t]{3}{*}{$\mathrm{HbA1c}$} & No & 76 & 7.65 & 1.58 & $0.003^{*}$ \\
\hline & NPDR & 85 & 7.81 & 1.53 & \\
\hline & PDR & 105 & 8.00 & 1.61 & \\
\hline \multirow[t]{3}{*}{ AGE } & No & 76 & 22.07 & 18.73 & $<0.001^{*}$ \\
\hline & NPDR & 85 & 26.49 & 16.15 & \\
\hline & PDR & 105 & 24.13 & 14.02 & \\
\hline \multirow[t]{3}{*}{ Total cholesterol } & No & 76 & 230.67 & 41.03 & $0.001^{*}$ \\
\hline & NPDR & 85 & 231.67 & 45.16 & \\
\hline & PDR & 105 & 239.36 & 47.46 & \\
\hline \multirow[t]{3}{*}{ Triglycerides } & No & 76 & 172.47 & 26.44 & $0.002^{*}$ \\
\hline & NPDR & 85 & 177.81 & 43.27 & \\
\hline & PDR & 105 & 179.98 & 33.29 & \\
\hline \multirow[t]{3}{*}{ HDL } & No & 76 & 49.18 & 11.72 & $0.001^{*}$ \\
\hline & NPDR & 85 & 47.64 & 11.61 & \\
\hline & PDR & 105 & 51.34 & 10.41 & \\
\hline \multirow[t]{3}{*}{ LDL } & No & 76 & 152.72 & 43.19 & $0.028^{*}$ \\
\hline & NPDR & 85 & 148.84 & 45.86 & \\
\hline & PDR & 105 & 151.28 & 47.10 & \\
\hline \multirow[t]{3}{*}{ Creatinine } & No. & 76 & 1.0 & 0.4 & $0.003^{*}$ \\
\hline & NPDR & 85 & 1.0 & 0.2 & \\
\hline & PDR & 105 & 0.9 & 0.2 & \\
\hline \multirow[t]{3}{*}{ Urea } & No. & 76 & 42.0 & 10.2 & $0.001 *$ \\
\hline & NPDR & 85 & 40.2 & 10.8 & \\
\hline & PDR & 105 & 36.9 & 6.6 & \\
\hline Lab. test & \multicolumn{2}{|c|}{ Comparison A ( $p$ value) } & \multicolumn{2}{|c|}{ Comparison B ( $p$ value) } & Comparison C ( $p$ value) \\
\hline $\mathrm{HbA1c}$ & \multicolumn{2}{|l|}{$0.017^{*}$} & \multicolumn{2}{|l|}{$0.002^{*}$} & 0.096 \\
\hline GEP & \multicolumn{2}{|l|}{$>0.001^{*}$} & \multicolumn{2}{|l|}{$>0.001^{*}$} & 0.275 \\
\hline Total Cholesterol & \multicolumn{2}{|l|}{0.055} & \multicolumn{2}{|l|}{$>0.001^{*}$} & 0.151 \\
\hline Triglycerides & \multicolumn{2}{|l|}{0.018} & \multicolumn{2}{|l|}{$>0.001^{*}$} & 0.347 \\
\hline $\mathrm{HDL}$ & \multicolumn{2}{|l|}{0.322} & \multicolumn{2}{|l|}{$>0.001^{*}$} & $0.014^{*}$ \\
\hline LDL & \multicolumn{2}{|l|}{0.23} & \multicolumn{2}{|l|}{$0.017^{*}$} & 0.607 \\
\hline Creatinine & \multicolumn{2}{|l|}{0.08} & \multicolumn{2}{|l|}{$0.001^{*}$} & 0.095 \\
\hline Urea & 0.21 & & $<0.001^{*}$ & & $0.015^{*}$ \\
\hline
\end{tabular}

*According to Table 2, microangiopathy (nephropathy and neuropathy) may not be clinically detected; however, investigations are needed for further diction. Comparison A between groups without retinopathy and that with NDPR.

Comparison B between groups without retinopathy and with PDR

Comparison $C$ between groups with NDPR and that with PDR

*(Kruskal-Wallis Test, Mann-Whitney $U$ with Bonferroni's adjustment: lower the significance of $P$ value from 0.05 to 0.017 ) 
Table 3 Genotype frequency of C-1214G polymorphism of SDH gene in patients with and without DR

\begin{tabular}{|c|c|c|c|c|c|c|c|c|}
\hline \multirow{2}{*}{\multicolumn{2}{|c|}{$\begin{array}{l}\text { Allele } \\
\text { Specific }\end{array}$}} & \multicolumn{2}{|c|}{ With retinopathy $(n=131)$} & \multicolumn{2}{|c|}{ Without retinopathy $(n=52)$} & \multirow[t]{2}{*}{ OR } & \multirow[t]{2}{*}{$(95 \% \mathrm{Cl})$} & \multirow{2}{*}{$\begin{array}{l}P \\
\text { value }\end{array}$} \\
\hline & & No. & $\%$ & No. & $\%$ & & & \\
\hline \multirow[t]{3}{*}{ Genotype } & GG & 31 & 25.2 & 11 & 21.2 & 0.80 & $(0.37-1.74)$ & 0.57 \\
\hline & CG & 69 & 56.1 & 37 & 71.2 & 1.93 & $(0.96-3.88)$ & 0.06 \\
\hline & $\mathrm{CC}$ & 23 & 18.7 & 4 & 7.7 & 0.36 & $(0.12-1.11)$ & 0.07 \\
\hline \multirow[t]{2}{*}{ Alleles } & G & 131 & 53.3 & 59 & 56.7 & 1.15 & $(0.73-1.83)$ & 0.55 \\
\hline & C & 115 & 46.7 & 45 & 43.3 & 0.87 & $(0.55-1.38)$ & \\
\hline
\end{tabular}

There was no significant difference in the genotype distribution $(C / C, C / G, G / G)$ of the $C-1214 G$ polymorphism between the two groups of patients with and without DR. Also, there was no significant difference of $G$ and $C$ allele frequencies

- Significant decrease in AGE between the groups without DR compared to DR (NPDR, PDR). No significant change in PDR group compared to NPDR (Table 2)

\section{Discussion}

The onset of diabetic retinopathy is multifactorial, and a cascade of hyperglycemia-linked pathways has been involved in the initiation and progression of this disease (Fu et al. 2016).

The results of this study revealed that the duration of diabetes is correlated to the occurrence of DR. There was a significant increase in HbA1c between groups with and without DR; also, there is a significant increase in HbA1c in PDR compared to NPDR. Highly statistically significant increase in HbA1c levels in both PDR and NPDR groups which agree with Lim (2019). Also, Aldebasi et al. (2011) detected a highly significant level of $\mathrm{HbA1c}$ in patients with PDR patients compared to NPDR. There was a significant increase in total cholesterol, HDL, TG, and glycated end product (AGE) in the PDR group compared to group without retinopathy. There was controversy results regarding the role of lipids in the pathogenesis of diabetic retinopathy. Chatziralli (2017). To the contrary, there was no statistically significant association of total cholesterol with DR. These results are consistent with several other studies, Ahmed et al. (2016) and Jayanthi et al. (2017). The Singapore Malay Eye study reported that higher cholesterol levels could have a good role in retinopathy, Wong et al. (2008), while CrosbyNwaobi and co-authors CrosbyNwaobi et al. (2015) reported no lipid profile association with progression of DR.

There was a significant increase in AGE in both PDR and NPDR groups compared to the group without retinopathy.

These results agreed with many studies (Giurdanella et al. 2017) (Saker et al. 2014), who postulated that AGE were localized to retinal blood vessels in diabetics and were correlated with the degree and clinical progression of retinopathy.(Giurdanella et al. 2017) and (Saker et al. 2014) found that AGE were elevated in various ocular tissues of diabetic subjects compared to diabetics without retinopathy (Navaratna et al. 2007) (Fan and Yan 2016).This includes vitreous collagen (Fan and Yan 2016), where the AGE levels correlate with diabetic retinopathy (Kim et al.

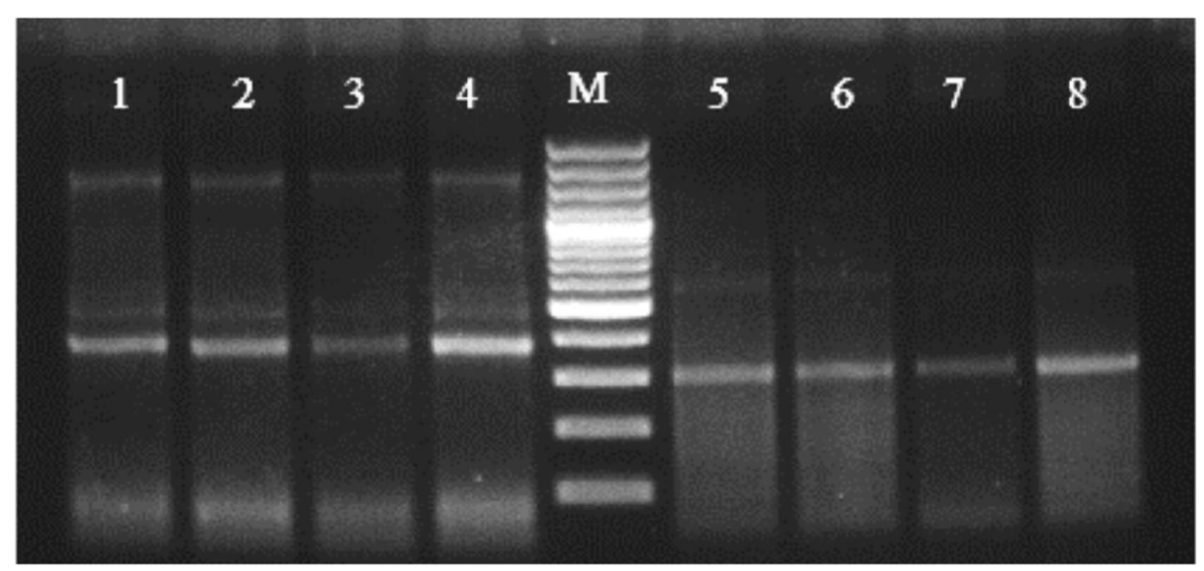

Fig. 1 Genotypes of the C/G polymorphism at the - 1214-bp SDH promoter region determined by allele-specific PCR detection (ASO-PCR) and analyzed by $2 \%$ agarose gel electrophoresis, stained with ethidium bromide, and viewed under gel documentation system. Lane $\mathrm{M}$ is the (100 bp) DNA ladder; lanes 1-4 show the result of amplification with primer specific to the G allele at $494 \mathrm{bp}$ and lanes 5-8 with primer specific to the $C$ allele 
Table 4 Distribution of genotype and alleles, and frequency of G-888C polymorphism of SDH gene in patients with and without DR

\begin{tabular}{|c|c|c|c|c|c|c|c|c|}
\hline \multirow[t]{2}{*}{ G888C } & & \multicolumn{2}{|c|}{ With retinopathy $(n=119)$} & \multicolumn{2}{|c|}{ Without retinopathy $(n=51)$} & \multirow[t]{2}{*}{ OR } & \multirow[t]{2}{*}{$(95 \% \mathrm{Cl})$} & \multirow{2}{*}{$\begin{array}{l}P \\
\text { value }\end{array}$} \\
\hline & & No. & $\%$ & No. & $\%$ & & & \\
\hline \multirow[t]{3}{*}{ Genotype } & GG & 71 & 59.7 & 36 & 70.6 & 1.62 & $(0.80-3.28)$ & 0.18 \\
\hline & GC & 40 & 33.6 & 13 & 25.5 & 0.68 & $(0.32-1.41)$ & 0.30 \\
\hline & CC & 8 & 6.7 & 2 & 3.9 & 0.57 & $(0.12-2.76)$ & 0.48 \\
\hline \multirow[t]{2}{*}{ Allele } & G & 182 & 76.5 & 85 & 83.3 & 1.54 & $(0.84-2.81)$ & 0.16 \\
\hline & C & 56 & 23.5 & 17 & 16.7 & 0.65 & $(0.36-1.19)$ & \\
\hline
\end{tabular}

There was no significant difference in the genotype distribution ( $C / C, G / C$, and $G / G)$ of the $G-888 C$ polymorphism between the two groups of patients with DR and without DR. However, the CC genotype occurred more frequently in patients with DR than patients without DR (6.7\% vs. $3.9 \%)$, and G/G genotype occurred more frequently in patients without DR than patients with DR (0.70.6 vs. 0.59.7)

2010). In the diabetic retina, AGE accumulation has been observed in vascular cells, neurons, and glia which may have pathogenic implications in retinal function (Radeva and Waschke 2018) (Prasain and Stevens 2009).

In diabetes, AGE accumulate in retinal pericytes which play an important role in the maintenance of microvascular homeostasis. Loss of pericytes could predispose the vessels to angiogenesis, thrombogenesis, and endothelial cell (EC) injury, thus leading to full clinical picture of diabetic retinopathy (Guo et al. 2009).

Wang et al. (2012) and van Hecke et al. (2005) demonstrated that the AGE-RAGE interaction induces ROS generation in cultured retinal pericytes inducing apoptotic cell death of pericytes. AGEs induced nuclear factor- $\mathrm{kB}(\mathrm{NF}-\mathrm{kB})$ activation and decreased the ratio of $\mathrm{Bcl}-2 /$ Bax increasing the activity of caspase-3, an enzyme responsible in the execution of apoptosis of pericytes. AGEs also upregulate RAGE mRNA levels in pericytes through the intracellular ROS generation (Joussen et al. 2004). van der Wijk et al. (2017) suggested the involvement of AGE in the development and progression of diabetic retinopathy by inducing VEGF over expression in pericytes. VEGF level was also found co-related with the breakdown of the blood-retinal barrier, thus being involved in retinal vascular hyper-permeability (Capitao and Soares 2016) and (Kaji et al. 2007). Furthermore, AGE interact with RAGE and directly stimulate growth and tube formation of microvascular ECs, the key steps of angiogenesis (Yamagishi et al. 2006) and (Nalini et al. 2017). It was also observed in (Huang et al. 2011) and (Aveleira et al. 2010) that the angiogenic activity of AGEs was mainly mediated by autocrine VEGF production by ECs. Studies have also shown that the AGE-RAGE interaction might increase VEGF gene transcription in micro vascular ECs by NADPH oxidasemediated ROS generation and subsequent NF- $\mathrm{KB}$ activation via Ras-MAPK pathway (Nalini et al. 2017).

Sorbitol dehydrogenase is the enzyme involved in polyol pathway. Li et al. (2019) had found an association of

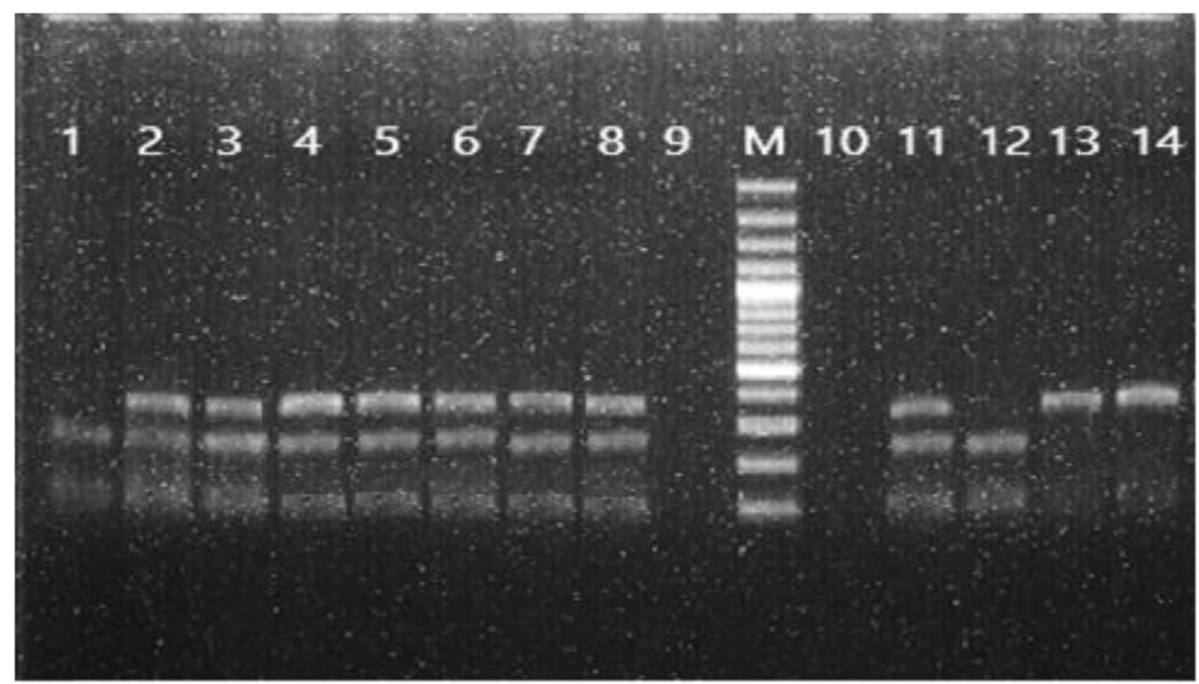

Fig. 2 Genotypes of the C/G polymorphism at the - 888-bp SDH promoter region determined by the PCR-based BseDI restriction fragment length polymorphism (RFLP-PCR) and analyzed by $2 \%$ agarose gel electrophoresis, stained with ethidium bromide, and viewed by gel documentation system. Lanes 1 and 12 show the result of amplification of G/G homozygote; lanes 13 and 14 show homozygote C/C; lanes 2, 3, $4,5,6,7,8$, and 11 show heterozygote $\mathrm{G} / \mathrm{C}$; lanes 9 and 10 are empty; lane $\mathrm{M}$ is (100 bp) the DNA ladder 
Table 5 The distribution of genotype frequency of G-888C polymorphism of SDH gene in relation to severity (NPDR and PDR) of retinopathy in both genders

\begin{tabular}{|c|c|c|c|c|c|c|c|c|}
\hline \multirow{2}{*}{\multicolumn{2}{|c|}{ Retinal state }} & \multicolumn{6}{|c|}{ G-888C } & \multirow{3}{*}{$\begin{array}{l}P \text { value } \\
0.488\end{array}$} \\
\hline & & \multicolumn{2}{|l|}{ GG } & \multicolumn{2}{|l|}{ GC } & \multicolumn{2}{|c|}{$\mathrm{CC}$} & \\
\hline \multirow[t]{3}{*}{ (Males) } & No & 12 & $80.0 \%$ & 3 & $20.0 \%$ & 0 & $0.0 \%$ & \\
\hline & NPDR & 13 & $54.2 \%$ & 10 & $41.7 \%$ & 1 & $4.2 \%$ & \\
\hline & PDR & 17 & $58.6 \%$ & 10 & $34.5 \%$ & 2 & $6.9 \%$ & \\
\hline \multirow[t]{3}{*}{ (Females) } & No & 24 & $66.7 \%$ & 10 & $27.8 \%$ & 2 & $5.6 \%$ & 0.932 \\
\hline & NPDR & 19 & $59.4 \%$ & 11 & $34.4 \%$ & 2 & $6.3 \%$ & \\
\hline & PDR & 22 & $64.7 \%$ & 9 & $26.5 \%$ & 3 & $8.8 \%$ & \\
\hline
\end{tabular}

There was no statistically significant influence of the three genotypes (GG, GC, and (C) polymorphism on DR progression in both genders. However, there was an increased frequency of CC genotypes polymorphism with severity in both genders $(0.0 \%, 4.2 \%, 6.9 \%)$ in males and $(5.6 \%, 6.3 \%, 8.8 \%)$ in females

genotype variant of SDH_1214-C-G (rs2055858) polymorphism that were associated with lower risk to DR in diabetic patients. These results agree with the results of this study.

Two polymorphisms described in the promoter region of the SORD gene, _1214C-G (rs2055858) and_888G-C (rs3759890), are in complete linkage disequilibrium and have been associated with the SORD gene expression in retinal cells in diabetes. These results agree with that reported in Amano et al. (2003), thus playing a role in the pathogenesis of DR. There was increased frequency of G_888_C polymorphism of SDH gene, and the frequency of $\mathrm{CC}$ genotype polymorphism increased severity in both genders. While the genotype frequency of $\mathrm{C}_{-}$ 1214_G polymorphisms of SDH gene, there was an increased frequency of CC genotype in females only. Also, the genotype and allele frequency of G_888_C polymorphisms of SDH gene were insignificant among the DR patient with and without retinopathy in type 1 diabetics. To our knowledge, there was no study investigating these associations of the genotype polymorphism in type 1 diabetes. The_888 GG genotype has been more frequently observed in patients with DR than in those without this

Table 6 Genotype frequency of C-1214G polymorphism of SDH gene in relation to severity (NPDR and PDR) of retinopathy in both genders

\begin{tabular}{|c|c|c|c|c|c|c|c|c|}
\hline \multirow{2}{*}{\multicolumn{2}{|c|}{ Retinal state }} & \multicolumn{6}{|c|}{ C-1214 G of SDH } & \multirow{3}{*}{$\frac{P \text { value }}{}$} \\
\hline & & \multicolumn{2}{|c|}{$\overline{C C}$} & \multicolumn{2}{|l|}{ CG } & \multicolumn{2}{|l|}{ GG } & \\
\hline \multirow[t]{3}{*}{ (Males) } & No & 3 & $20.0 \%$ & 10 & $66.7 \%$ & 2 & $13.3 \%$ & \\
\hline & NPDR & 1 & $4.2 \%$ & 16 & $66.7 \%$ & 7 & $29.2 \%$ & \\
\hline & PDR & 6 & $20.7 \%$ & 16 & $55.2 \%$ & 7 & $24.1 \%$ & \\
\hline \multirow[t]{3}{*}{ (Females) } & No & 1 & $2.7 \%$ & 27 & $73.0 \%$ & 9 & $24.3 \%$ & 0.05 \\
\hline & NPDR & 7 & $21.9 \%$ & 15 & $46.9 \%$ & 10 & $31.3 \%$ & \\
\hline & PDR & 9 & $23.7 \%$ & 22 & $57.9 \%$ & 7 & $18.4 \%$ & \\
\hline
\end{tabular}

There was no statistically significant difference between the three genotypes $(C C, C G$, and GG) in relation to DR severity in male genders. However, there was a statistically significant difference in female gender with increased frequency of CC genotype $(2.7 \%, 21.9 \%$, and $23.7 \%)$ complication among Japanese patients (Amano et al. 2003). Based on these findings and that both polymorphisms are linked, we investigated whether the _888G > C polymorphism in the SORD gene is associated with the presence or severity of DR in patients with typeldiabetes.

\section{Conclusion}

The onset of diabetic retinopathy is multifactorial, and a cascade of hyperglycemia-linked pathways has been involved in the initiation and progression of this disease. The biochemical process of advanced glycation appears to be enhanced in diabetes due to hyperglycemia along with oxidative stress and lipids. Further research is required to understand the cellular and molecular processes and to firmly establish whether AGEs are direct contributors in the initiation and progression of diabetic retinopathy. So that novel anti-AGE strategies can be developed, aiming to reduce the major economical and medical burden caused by diabetic retinopathy.

\begin{tabular}{|c|c|}
\hline \multicolumn{2}{|l|}{ 1-Medical equipment } \\
\hline Source & equipment \\
\hline 1-Pcr (TProfessional Basic) & $\begin{array}{l}\text { Research Institute of } \\
\text { Ophthmology (RIO) }\end{array}$ \\
\hline $\begin{array}{l}\text { 2-Gel Electrophoresis unit used in } \\
\text { this study was provided by } \\
\text { Biometra, Germany (Model: } \\
\text { Compact M). }\end{array}$ & $\begin{array}{l}\text { Research Institute of } \\
\text { Ophthmology (RIO) }\end{array}$ \\
\hline 3-Robonik Spectrophotometer & $\begin{array}{l}\text { Research Institute of } \\
\text { Ophthmology (RIO) }\end{array}$ \\
\hline Kit & Source \\
\hline Blood sample & $\begin{array}{l}\text { Research Institute of } \\
\text { Ophthmology (RIO) }\end{array}$ \\
\hline Glucose & Biomerieux, ca 61-269(France). \\
\hline Glycosylated Hemoglobin (HbA1c) & NS Biotec (Egypt). \\
\hline 4-Cholesterol & $\begin{array}{l}\text { Spectrum Diagnostics } 225003 \\
\text { (Egypt). }\end{array}$ \\
\hline 5-Triglycerides & $\begin{array}{l}\text { Spectrum Diagnostics } 314009 \\
\text { (Egypt) }\end{array}$ \\
\hline 6-HDL Cholesterol & $\begin{array}{l}\text { Spectrum Diagnostics } 267 \\
\text { 002(Egypt). }\end{array}$ \\
\hline 7-LDL Cholesterol: & Spectrum Diagnostics (Egypt). \\
\hline 8-glycation end products & $\begin{array}{l}\text { akit supplied by cell biolabs, CA } \\
\text { 92126, San Diego, and (USA). }\end{array}$ \\
\hline 9-DNA extraction & $\begin{array}{l}\text { (Gene JET Whole Blood Genomic } \\
\text { DNA Purification Mini Kit) Thermo } \\
\text { Scientific, (EU) Lithuania }\end{array}$ \\
\hline \multirow[t]{2}{*}{ 10-Dream Taq DNA polymerase } & Thermo Scientific \\
\hline & Thermo Scientific \\
\hline $\begin{array}{l}\text { 11-Agarose } \mathrm{A} \text { and Tis-Borate-EDTA } \\
\text { (TBE) }\end{array}$ & Biobasic, Canada \\
\hline 12-GeneRuler 20 bp & Thermo Scientific \\
\hline
\end{tabular}




\section{Abbreviations}

DR: Diabetic R etinopathy; PDR: Proliferative diabetic retinopathy; TNFa: Tumor necrosis factor alpha; BRB: Blood-retinal barrier; HbA1c: Glycated hemoglobin; NPDR: Non-proliferative diabetic retinopathy; AGE: Advanced glycation end products; SDH: Sorbitol dehydrogenase; RFLP: Restriction fragment length polymorphism; FBS: Fasting blood sugar; FFA: Fluorescein fundus angiography; HDL: High density lipoprotein; LDL: Low density lipoprotein; ELISA: Immune-sorbent assay; EDTA: Ethylene diamine tetra acetic acid

\section{Authors' contributions}

1- Leqaa A. Moemen: Developing the research idea of scientific and legal aspects and supervising the practical part and writing the texet. 2- Mona A.Abdel Hamid: Developing the research idea of scientific and legal aspects and supervising the practical part and writing the texet. 3- Soher Abdel Wahab: supervising the practical part. 4- Mahmoud Kenawy M. Kenawy: Doing the analysis part. 5- Manal H. Abuelela: Make the statistical analysis. 6Olfat A. Hassanin: Diagnosis of diabetic patients and those diabetic retinopathy. 7- Marwa A. Fouly: Diagnosis of diabetic patients and those diabetic retinopathy by fluorescein angiography. 8- Amira A. Abdel azeem: Supervising the part of the practical and theoretical genetic work. 9- Shahira Riad Noweir: Supervising the part of the practical and theoretical genetic work. 10- SomaiaM. Ismail: Supervising the part of the practical and theoretical genetic work. 11- Yara Hossam Eldin R.Abdel Gawad: Help make the statistical analysis. 12- Safa Refaat: Diagnosis of patients of diabetic retinopathy. 13- Azza K. Amer: Supervising routine laboratory investigations. 14- Nervana A Khalaf: Supervising the part of the practical., and help in writing. 15- Safya H Aboelmakarem: routine laboratory investigations. 16Mehry S Elsobky: routine laboratory investigations. 17- Mona R Abdelrasool: routine laboratory investigations. 18- Sherif. S. Karawya: Diagnosis of diabetic patients and diabetic retinopathy by fluorescein angiography. 19- Zeinab M. Osman: Diagnosis of patients of diabetic retinopathy. The author(s) read and approved the final manuscript.

\section{Funding}

The authors declare that they do not have any funds.

\section{Availability of data and materials}

All authors declare that the data and material are available. The study protocol was performed according to the Helsinki declaration as regards human guideline.

\section{Ethics approval and consent to participate}

The study was approved by the ethical committee of the Research Institute of Ophthalmology.

\section{Consent for publication}

All authors declare that they approved the publication of this research in the Bulletin of National Research Center.

\section{Competing interests}

The authors declare that they have no competing interests.

\begin{abstract}
Author details
${ }^{1}$ Medical Biochemistry, Research institute of Ophthalmology, Giza, Egypt. ${ }^{2}$ Public Health Department, Research institute of Ophthalmology, Giza, Egypt. ${ }^{3}$ Medical Retina Department, Research institute of Ophthalmology, Giza, Egypt. ${ }^{4}$ Ophthalmic Genetics, Research institute of Ophthalmology, Giza, Egypt. ${ }^{5}$ National Research Center, Giza, Egypt. ${ }^{6}$ Internal Medicine unit, Research institute of Ophthalmology, Giza, Egypt. ${ }^{7}$ Clinical and Chemical Pathology Department, Research institute of Ophthalmology, Giza, Egypt.
\end{abstract}

Received: 10 December 2019 Accepted: 23 March 2020

Published online: 19 April 2020

\section{References}

Ahmed J, Mulla MZ, Arfat YA (2016) Thermo-mechanical, structural characterization and antibacterial performance of solvent casted polylactide/ cinnamon oil composite films. Food Control 69:196-204
Aldebasi Y, Mohieldein A, Almoteri YAB (2011) Imbalance of oxidant/antioxidant status and risk factors for Saudi type 2 diabetic patients with retinopathy. $\mathrm{Br}$ J Med Med Res 1(4):371-384.I

Amano H, Hayashi I, Endo H, Kitasato H, Yamashina S, Maruyama T et al (2003) Host prostaglandin E2-EP3 signaling regulates tumor-associated angiogenesis and tumor growth. J Exp Med 197(2):221-232

American Diabetes Association (2010) Diagnosis and classification of diabetes mellitus. Diabetes Care 33(Supplement 1):S62-S69

Aveleira CA, Lin CM, Abcouwer SF, Ambrosio AF, Antonetti DA (2010) TNF-alpha signals through PKCzeta/NF-kappaB to alter the tight junction complex and increase retinal endothelial cell permeability. Diabetes 59:2872-2882

Capitao M, Soares R (2016) Angiogenesis and inflammation crosstalk in diabetic retinopathy. J Cell Biochem 117:2443-2453

Chatziralli IP (2017) The role of dyslipidemia control in the progression of diabetic retinopathy in patients with type 2 diabetes mellitus. Diabetes Therapy 8(2):209-212

Choudhuri S, Dutta D, Sen A, Chowdhury IH, Mitra B, Mondal LK, Saha A, Bhadhuri G, Bhattacharya B (2013) Role of N-epsilon- carboxy methyl lysine, advanced glycation end products and reactive oxygen species for the development of nonproliferative and proliferative retinopathy in type 2 diabetes mellitus. Mol Vis 19:100-113

Crosby-Nwaobi R, Malik AN, Parsade CK, Ajaz S, Gnudi L, Czajka A, Sivaprasad S (2015) Altered circulating mitochondrial DNA and increased inflammation in patients with diabetic retinopathy. Diabetes Res Clin Pract 110(3):257-265

Fan L, Yan H (2016) FTY720 Attenuates retinal inflammation and protects bloodretinal barrier in diabetic rats. Invest Ophthalmol Vis Sci 57:1254-1263

Fu D, Yu JY, Yang S, Wu M, Hammad SM, Connell AR, Du M, Chen J, Lyons TJ (2016) Survival or death: a dual role for autophagy in stress-induced pericyte loss in diabetic retinopathy. Diabetologia 59:2251-2261

Giurdanella G, Lazzara F, Caporarello N, Lupo G, Anfuso CD, Eandi CM, Leggio GM, Drago F, Bucolo C, Salomone S (2017) Sulodexide prevents activation of the PLA2/COX-2NEGF inflammatory pathway in human retinal endothelial cells by blocking the effect of AGE/RAGE. Biochem Pharmacol 142:145-154

Guo X, Wang L, Chen B, Li Q, Wang J, Zhao M, Wu W, Zhu P, Huang X, Huang Q (2009) ERM protein moesin is phosphorylated by advanced glycation end products and modulates endothelial permeability. Am J Physiol Heart Circ Physiol 297:H238-H246

Huang H, Gandhi JK, Zhong X, Wei Y, Gong J, Duh EJ, Vinores SA (2011) TNFa is required for late BRB breakdown in diabetic retinopathy, and its inhibition prevents leukostasis and protects vessels and neurons from apoptosis. Invest Ophthalmol Vis Sci 52(3):1336-1344

Jayanthi VSA, Das AB, Saxena U (2017) Recent advances in biosensor development for the detection of cancer biomarkers. Biosens Bioelectron 91: $15-23$

Jing G, Wang JJ, Zhang SX (2012) ER stress and apoptosis: a new mechanism for retinal cell death. Exp Diabetes Res 2012:589589

Joussen AM, Poulaki V, Le ML, Koizumi K, Esser C, Janicki H, Schraermeyer U, Kociok N, Fauser S, Kirchhof B, Kern TS, Adamis AP (2004) A central role for inflammation in the pathogenesis of diabetic retinopathy. FASEB J 18:14501452

Kaji Y, Usui T, Ishida S, Yamashiro K, Moore TC, Moore J, Yamamoto Y, Yamamoto $H$, Adamis AP (2007) Inhibition of diabetic leukostasis and blood-retinal barrier breakdown with a soluble form of a receptor for advanced glycation end products. Invest Ophthalmol Vis Sci 48:858-865

Kandarakis SA, Piperi C, Topouzis F, Papavassiliou AG (2014) Emerging role of advanced glycation-end products (AGEs) in the pathobiology of eye diseases. Prog Retin Eye Res 42:85-102

Katagiri M, Shoji J, Inada N, Kato S, Kitano S, Uchigata Y (2017) Evaluation of vitreous levels of advanced glycation end products and angiogenic factors as biomarkers for severity of diabetic retinopathy. Int Ophthalmol. https://doi. org/10.1007/s10792-017-0499-1

Kim J, Kim KM, Kim CS, Sohn E, Lee YM, Jo K, Kim JS (2012) Puerarin inhibits the retinal pericyte apoptosis induced by advanced glycation end products in vitro and in vivo by inhibiting NADPH oxidase-related oxidative stress. Free Radic Biol Med 53:357-365

Kim JH, Kim JH, Jun HO, Yu YS, Kim KW (2010) Inhibition of protein kinase C delta attenuates blood-retinal barrier breakdown in diabetic retinopathy. Am J Pathol 176:1517-1524

Li W, Chen S, Mei Z, Zhao F, Xiang Y (2019) Polymorphisms in sorbitol-aldose reductase (Polyol) pathway genes and their influence on risk of diabetic retinopathy among Han Chinese. Med Sci Monitor 25:7073 
Lim F (ed) (2019) Biomedical applications of microencapsulation. CRC press

Liu WY, Tzeng TF, Liu IM (2016) Zerumbone, a bioactive sesquiterpene, ameliorates diabetes-induced retinal microvascular damage through inhibition of phospho-p38 mitogen-activated protein kinase and nuclear factor-kappaB pathways. Molecules 21

Madonna R, Balistreri CR, Geng YJ, De Caterina R (2017) Diabetic microangiopathy: pathogenetic insights and novel therapeutic approaches. Vasc Pharmacol 90:1-7

Nalini M, Raghavulu BV, Annapurna A, Avinash P, Chandi V, Swathi N (2017) Wasim: Correlation of various serum biomarkers with the severity of diabetic retinopathy. Diabetes Metab Syndr 11(Suppl 1):S451-S454

Navaratna D, McGuire PG, Menicucci G, Das A (2007) Proteolytic degradation of VE-cadherin alters the blood-retinal barrier in diabetes. Diabetes 56:23802387

Onarato C, Nakano K, Nakamura N, Kitagawa Y, Shigeta H, Hasegawa G et a (2000) Advanced glycation end products induce expression of vascular endothelial growth factor by retinal Müller cells. Biochem Biophys Res Commun 236(3):712-715

Prasad K, Mishra M (2018) AGE-RAGE Stress, stressors, and antistressors in health and disease. Int J Angiol 27:1-12

Prasain N, Stevens T (2009) The actin cytoskeleton in endothelial cell phenotypes. Microvasc Res 77:53-63

Pusparajah P, Lee LH, Abdul Kadir K (2016) Molecular markers of diabetic retinopathy: potential screening tool of the future? Front Physiol 7:200

Radeva MY, Waschke J (2018) Mind the gap: mechanisms regulating the endothelial barrier. Acta Physiol (Oxf):222

Romeo G, Liu WH, Asnaghi V, Kern TS, Lorenzi M (2002) Activation of nuclear factor-kappaB induced by diabetes and high glucose regulates a proapoptotic program in retinal pericytes. Diabetes 51:2241-2248

Saker S, Stewart EA, Browning AC, Allen CL, Amoaku WM (2014) The effect of hyperglycaemia on permeability and the expression of junctional complex molecules in human retinal and choroidal endothelial cells. Exp Eye Res 121: 161-167

Takeuchi M, Yamagishi S (2009) Involvement of toxic AGEs (TAGE) in the pathogenesis of diabetic vascular complications and Alzheimer's disease. J Alzheimers Dis 16:845-858

van der Wijk AE, Hughes JM, Klaassen I, Van Noorden CJF, Schlingemann RO (2017) Is leukostasis a crucial step or epiphenomenon in the pathogenesis of diabetic retinopathy? J Leukoc Biol 102:993-1001

van Hecke MV, Dekker JM, Nijpels G, Moll AC, Heine RJ, Bouter LM, Polak BC, Stehouwer CD (2005) Inflammation and endothelial dysfunction are associated with retinopathy: the Hoorn Study. Diabetologia 48:1300-1306

Wan TT, Li XF, Sun YM, Li YB, Su Y (2015) Recent advances in understanding the biochemical and molecular mechanism of diabetic retinopathy. Biomed Pharmacother 74:145-147

Wang L, Li Q, Du J, Chen B, Li Q, Huang X, Guo X, Huang Q (2012) Advanced glycation end products induce moesin phosphorylation in murine retinal endothelium. Acta Diabetol 49:47-55

Warboys CM, Toh HB, Fraser PA (2009) Role of NADPH oxidase in retinal microvascular permeability increase by RAGE activation. Invest Ophthalmol Vis Sci 50:1319-1328

Wong MA, Deegan JI, Lomax J, Ashburner M, Tweedie S, Carbon S et al (2008) The gene ontology project in 2008. Nucleic Acids Res 36:D440-D444

Yamagishi SI, Nakamura K, Matsui T, Inagaki Y, Takenaka K, Jinnouchi Y et al (2006) Pigment epithelium-derived factor inhibits advanced glycation end product-induced retinal vascular hyperpermeability by blocking reactive oxygen species-mediated vascular endothelial growth factor expression. J Biol Chem 281(29):20213-20220

\section{Publisher's Note}

Springer Nature remains neutral with regard to jurisdictional claims in published maps and institutional affiliations.

\section{Submit your manuscript to a SpringerOpen ${ }^{\circ}$ journal and benefit from:}

- Convenient online submission

- Rigorous peer review

- Open access: articles freely available online

- High visibility within the field

- Retaining the copyright to your article

Submit your next manuscript at $\boldsymbol{\nabla}$ springeropen.com 